\title{
Effects of Voluntary Immigration on the Distribution of Autobiographical Memory over the Lifespan
}

\author{
ROBERT W. SCHRAUF ${ }^{1}$ and DAVID C. RUBIN ${ }^{2}$ \\ ${ }^{1}$ Buehler Center on Aging, Northwestern University Medical School, USA \\ ${ }^{2}$ Department of Psychology: Experimental, Duke University, USA
}

\begin{abstract}
SUMMARY
Immigration may be considered a 'traumatic' event with acute phases followed by long latency effects. Ten older, Hispanic adults who immigrated to the USA at ages 20-22, 24-28, and 34-35 narrated their 'life-stories' on two occasions, once in English and once in Spanish. Instead of the usual reminiscence bump they showed an increase in autobiographical recalls corresponding specifically to their ages at immigration. Each of the narrated life stories was independently coded for amount of detail, emotional valence, status as transitional event, and backward/forward search strategy. Memories for the time of immigration did not differ from other memories on any of these ratings. Increased recall for the period of immigration may be due to the encoding of novel events and the 'effort after meaning' required to integrate these events followed by a relatively stable period (settlement) marked by release from proactive interference and spaced rehearsal. Copyright (C) 2001 John Wiley \& Sons, Ltd.
\end{abstract}

Popular and psychological understandings describe trauma as a violent shock to the mental organism, which overtaxes normal abilities to assimilate and integrate the experience. Sequelae include subsequent attempts to accomplish such hermeneutic integration. The experience of immigration would be traumatic only in an analogous sense, and Grinberg and Grinberg (1989) in Psychoanalytic Perspectives on Immigration and Exile make precisely this case. In effect, they argue that immigration does include an acute phase followed by cumulative events and tension traumas that prolong the psychic conflicts initially produced. They further argue that immigration shares with other traumatic events a delayed impact: 'It is even generally the case for there to be what is called a latency period of indeterminable length between traumatic events and their detectable aftereffects, just as one observes a delayed mourning period in cases of migrations' (p. 12). In this paper we take up this 'analogous view' of immigration as trauma in order to examine its effects on the encoding and retrieval of autobiographical memories. This is in no way meant to dilute the tragedy of individual or social traumas; our approach draws, however, on parallel psychological dynamics. *Correspondence to: Robert W. Schrauf, Buehler Center on Aging, 750 North Lake Shore Drive, Suite 601,
Chicago, IL 60611-2611, USA. E-mail: r.schrauf@northwestern.edu

Contract grant sponsor: National Institute of Aging.

Contract grant number: AG16340-01A1. 
Our concern is with the macrostructure of autobiographical memory or the distribution of autobiographical memories over the lifespan. This distribution has been found to be remarkably stable across individuals (Rubin, 1998, in press; Rubin and Schulkind, 1997a,b; Rubin et al., 1986). It comprises three components. A retention function describes enhanced encoding and retrieval of memories from the most recent ten years of life. Childhood amnesia refers to the general inaccessibility of memories from before the ages of three or four. Finally, and most apposite here, the reminiscence phenomenon or 'reminiscence bump' describes a greater-than-expected number of recalls for events from between the ages of 10-30. (This increase creates a 'bump' in histograms portraying memory distributions.)

Various theories have been advanced to explain this 'bump'. A maturational-biological account would argue that cognitive capacities are at their optimum during the ages 10-30-probably due to faster processing. Studies in cognitive ageing suggest that processing speed decreases among older adults relative to younger adults, and that this decrease may be casually related to various deficits (Cerella, 1985; Hale and Myerson, 1995; Salthouse, 1996). Memory for events during this time may be enhanced because the organism itself is more cognitively efficient and sensitive. Standardized tests show memory and fluid intelligence peaks in this period (Rubin et al., 1998).

An identity account has been offered by Fitzgerald and his colleagues. This explanation argues that late youth and early adulthood is a time during which identity formation is a key developmental task and that more memories are encoded during this time (Elnick et al., 1999; Fitzgerald, 1986, 1988, 1992, 1996).

Rubin and his colleagues (Rubin et al., 1998; Schrauf and Rubin, 1998) have proposed a cognitive mechanisms account that argues that the optimal conditions for memory encoding and retrieval obtain when a period of rapid change is followed by a period of relative stability. During a period of change many novel, distinctive events occur, and these require more 'effort after meaning' (Bartlett, 1932). Novelty and effort after meaning benefit memory encoding. In a subsequent period of relative stability, the retrieval of such events is optimized by a more stable mental organization, spaced rehearsal, and release from proactive interference. Proactive interference suggests that as the number of similar new items-to-be-learned increases, the ease of later retrieval decreases. Thus, a release from proactive interference, applied to the reminiscence phenomenon, describes that situation (young adulthood) in which remembering follows a time when many dissimilar items are learned (adolescence and youth).

Two recent attempts have been made to test for the 'bump' in populations that have experienced major life events outside the bump period. In a study of bilingual autobiographical memory in older adult immigrants, Schrauf and Rubin (1998) tested older Hispanic adults (aged 61-69) who immigrated to the USA in adulthood. This study employed a word-cuing technique to induce retrievals in two separate language sessions for each participant. For purposes of analysis, individuals were grouped by age at immigration (20-24, 26-30, 34-35) and memories plotted. For the earliest group of immigrators, immigration coincided with the traditional bump. By contrast, the late group of immigrators showed a bump for the time of immigration and a diminished number of recalls for the traditional bump period. In line with their cognitive mechanisms account, Schrauf and Rubin theorized that immigration represented a period of novelty followed by a stable period (settlement) of memory organization that enhanced encoding. 
Conway and Haque (1999) compared younger and older groups of Bangladeshis and found that persons aged 20-42 displayed the usual increase in the number of memories between ages 10 and 30 but that persons aged 46-86 showed a second increase for ages 35-55. This latter period corresponds to the period of the Bangladeshi war with Pakistan resulting in Bangladeshi independence. The authors account for both bumps by arguing that development of generational identity and 'the emergence of an integrative self with the establishment of life goals' triggers the operation of a process of privileged encoding' (Conway and Haque, 1999, p. 41).

Interestingly, the authors asked participants to self-rate their memories for their importance to the self, the intensity of emotion, frequency of rehearsal, and novelty. Mean scores for these characteristics of memories in each decade of life $(0-10,10-20$, 20-30, etc.) showed no significant differences between decades. Thus, increased encoding during 'bump' periods is not due to the affective character, novelty, importance, or frequency of rehearsal of the memories. This is consistent with other work on such ratings (Rubin and Schulkind, 1997a). The Conway and Haque study is important for its examination of what is certainly a critical, stressful, and traumatic event in the lives of the participants. Notably a second period of greater-than-expected retrievals attends a time of social upheaval and personal uncertainty and re-adaptation.

Both the Conway and Haque and the Schrauf and Rubin studies suggest that critical, stressful, and potentially traumatic, events do indeed affect the distributions of autobiographical memory by inducing secondary periods of enhanced encoding and subsequent retrieval. Both studies employ the word-cuing technique to induce recalls. Thematically, the present study focuses more intently on immigration as the manipulation of memory distributions because immigration possesses the unique feature of prolonging the period of psychological adaptation, resistance, and adjustment (Schrauf, in press). Methodologically, it moves from word cuing and self-rating of the phenomenological features of memory to narrative recall and post-hoc coding of narratives by objective observers.

In terms of method, the advantage of the cuing technique is that it provides a random sample of autobiographical memory (Crovitz and Schiffman, 1974). It samples in an unbiased fashion either the underlying contents of autobiographical memory or, more conservatively, the default pattern of retrieval when retrieval is unconstrained. Having people rate the phenomenological features of their memories (intensity, etc.) provides personal evaluation of memories. The weakness is that these methods are somewhat artificial: memories are cued and retrieved but are not placed in any particular context, and so retrieval is (designedly) capricious. Successive retrievals are just another laboratory exercise. Self-ratings are non-contextualized and assume that memories have properties as isolates or atomic entities irrespective of the uses to which they are put. However, personal memories probably represent the self-concept of the person at the time of recall (Barclay, 1986; Barclay and Subramanian, 1987; Barclay and Wellman, 1986), reflecting crucially the fact that recall is most often purposeful and socially motivated (Schrauf, 1997).

Narrative recall, on the other hand, possesses the virtue of greater ecological validity; that is, people in various situations in real life provide life-stories, and it has been argued that to exist socially a person must have a coherent life story (Linde, 1993). The weakness of narrative recall is that it is not a random sampling of the autobiographical memory base but a consciously patterned retrieval strategy governed broadly by the retrieval strategy of forward search and the necessity for creating coherence. This offers a particular advantage 
to this study in that it increases the likelihood that distributions will display greater individual variance due to both conscious editing and the creation of coherence, and these factors should count against the hypotheses advanced below. Previous work with narrative recall protocols (Fromholt and Larsen, 1991; Fromholt et al., 1995) has shown that narratives of older adults produce a memory distribution similar to that of the word-cuing method, but with a reduced retention component. Recent events do not contribute as heavily to the life narrative of older adults.

Thematically, this study focuses on immigration because it is different in kind from most 'traumatic' changes in which an individual experiences a striking disruption of life after which he or she is socially required to re-adapt to 'normal' circumstances. In the case of immigration the circumstances and conditions of change are permanent. Thus, as the Grinbergs argue, the main event is followed by cumulative disruptions and tension traumas, and possibly latent effects, which emerge later. Acculturation and second language acquisition can involve extensive cognitive consequences as changes in worldview, ethnopsychology, and language socialization affect the cognitive integration, organization, and production of new knowledge about the self and society (Schrauf, in press). It seems logical to predict consequences attendant on immigration for both the cognitive functioning of memory as well as effects on the contents of memory.

\section{COGNITIVE FUNCTIONING}

If immigration and settlement produce the reminiscence phenomenon as does adolescence and early adulthood, then we would expect increased encoding of memories and more detailed memories for this important period of life. Furthermore, research on life narratives of the elderly suggest that persons most often tell their stories according to the cultural representation of a 'normal' life course: an expectable sequence of events across the lifespan (Neugarten et al., 1965; Settersten, 1997; Settersten and Hagestad, 1996; Settersten and Mayer, 1997). Where coherence in the life narrative is more difficult to establish (where unexpected events, dilemmas, sufferings and unaccountable happenings are more prevalent), individuals more often abandon the chronological structure and tell their stories according to personal themes (Luborsky, 1987, 1993a,b; 1998). Because immigration (whether voluntary or involuntary) may be conceived as a major discontinuity in a person's life, we expect therefore more evidence of doubling back and backward search for memories than straightforward adherence to chronologically governed accounts.

\section{CONTENTS OF MEMORY}

Because the immigrant's sense of competence and adequacy are challenged and his or her sense of social identity undergoes a forced change, this period is probably more emotionally stressful than earlier and later periods. We expect therefore that memories for the time of immigration will be more emotionally marked. Finally, it is arguable that during the time immediately prior to and after the act of immigration many more events would occur that would shape future patterns of adaptation and survival. We call these 'transitional events' (Pillemer, 1998) and predict a greater preponderance of them for the years just before immigration and just afterwards. 
We predict that immigration will have the following effects on autobiographical memories:

Hypothesis 1: Immigrants' narratives will reproduce the distribution of memories seen in cuing techniques. That is there will be a reminiscence bump reflecting disproportionately more numerous retrieval of memories corresponding to the time of immigration and settlement than would be expected by the retention function. The increase in retrievals corresponding to the time of immigration will overshadow the traditional reminiscence bump. Hypothesis 2: Given the importance of the period of immigration and settlement for the remainder of life, memories from this period will be more detailed than older or more recent memories.

Hypothesis 3: Memories for the period of immigration and settlement will be more emotionally marked than memories from other periods of life.

Hypothesis 4: A greater proportion of memories for pattern-setting events or events bringing about changes in a person's life ('transitional events') will be recounted for the period corresponding to immigration and settlement.

Hypothesis 5: Explaining and ordering the events of immigration will occasion more backward searches for memories than at other times of life.

\section{METHODS}

Ten older adult immigrants, 8 female, mean age $=64.5(S D=2.5)$, participated in the study. These were from Argentina (2), Cuba (3), Guatemala (1), Panama (1), and Spain (2). Mean age at immigration was 27.5 years $(S D=5.5)$ with the mean number of years in the USA as $37.0(S D=3.7)$. Mean years of education were $15.3(S D=1.8)$. Participants were recruited for an earlier study of bilingual autobiographical memory (Schrauf and Rubin, 1998, 2000). For more details on these participants, see participant numbers $1-4,6-7$, 8-11 in Tables 1, 2, and 3 of Schrauf and Rubin (1998).

Narrative interviews were conducted by the bilingual first author in homes of participants or at Duke University, depending on their preference. Participants were asked to recount the story of their lives while being recorded. Once the session began, the interviewer did not prompt for any memories, make any comments, or ask any questions. Participants talked for between 30 and 45 minutes. Every participant constructed his or her account according to a chronological framework and signalled a natural end to the account by saying things like 'And that's it' or 'That's my life. Should I say more?'

Reactivity to the researcher and the task was judged to be low since by this time in the study, persons had participated in a series of four experimental sessions over a period of 10 months with the same interviewer, the last of these session being about 3 months before those reported here. The participants understood the nature of the study as having to do with bilingualism, and in fact each participant told his or her life-story twice: once in Spanish and once in English (mean days between sessions $=67.50 ; S D=16.69$ ). Although the language data does not contribute to the analyses done in this paper, from a methodological point of view it is interesting to note that the idiosyncrasies possible in one telling are controlled for by having two life-stories for each participant. Participants were paid $\$ 50$ dollars for their participation in the two sessions of the study.

All tapes were transcribed by 2 persons fluently bilingual in English and Spanish. These same individuals coded transcripts. Interrater agreement for coding the variables was between 0.81 and 1.0 . 


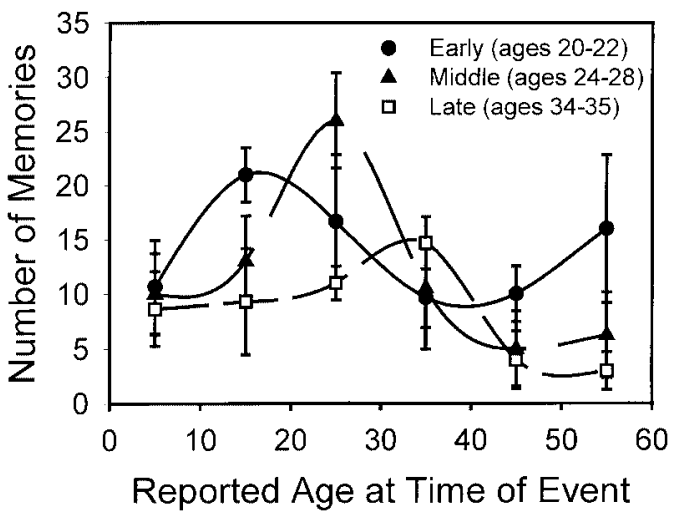

Figure 1. Histogram of autobiographical memories of immigrants to the USA grouped according to age at immigration. Error bars show standard errors

\section{RESULTS}

\section{The distribution of memories across the lifespan}

For purposes of analysis, the 10 participants were grouped by age at immigration into two groups: early immigrators (ages 20, 21, 22), middle immigrators (ages 24, 26, 28, 30), and late immigrators (ages 34, 35, 35), and their memories plotted across the lifespan. Figure 1 shows the distributions of the memories of these groups across the lifespan. The early immigrators show an increase of memories in the bin corresponding to the second decade of life, the middle immigrators in the bin corresponding to the third decade of life, and the late immigrators in the bin corresponding to the fourth decade of life. The same pattern of increased age of the bump was seen with word-cued memories in our earlier work (Schrauf and Rubin, 1998, Figure 2). Because of the small number of immigrants in each age group and in order to better portray the effect of immigration on the distribution of memories, we

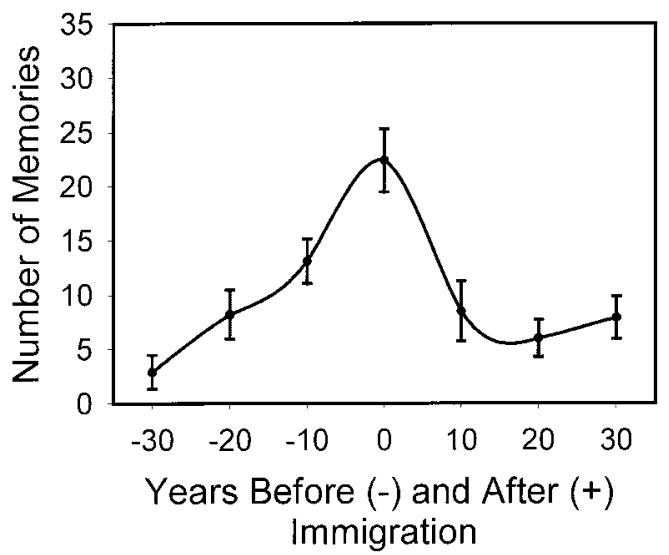

Figure 2. Histogram of autobiographical memories of immigrants with year of immigration set to zero, memories from before immigration to the left $(-)$, and memories after immigration to the right $(+)$. Error bars show standard errors 
set each individual's age at immigration to zero and graph the memories relative to the date of immigration (Figure 2).

The point plotted above zero represents all those memories that occurred in the ten-year period including five years before immigration $(-)$ and those occurring five years after $(+)$ immigration. Since all the individuals in this study were voluntary immigrants, the five years before immigration include the time of decision making, anticipation, and planning for emigration. The five-year period afterwards includes the initial years of acculturation in the new environment and language learning. Thus, this ten-year period reflects the time of most intense change and adaptation resulting from leaving their homelands and settling in the USA. The point above the number -10 represents the ten-year period in the homeland before immigration and initial settlement; the point above +10 represents the ten-year period in the USA beginning after five years of settlement and ending fifteen years into life in the USA. The most extreme point to the left of zero ( -30$)$ must be viewed with caution because persons in the early group of immigrators were of course not born yet and have no memories represented at this point.

The number of memories recounted for the period of immigration is significantly higher $(M=22.40 ; S D=9.23)$ than for those of the ten-year period that immediately follows it and which corresponds to later life in the USA $(M=8.50 ; S D=8.78 ; t(9)=4.49$, $p<0.01)$. Likewise memories for the period of immigration outnumber those of the ten-year period of life in the homeland immediately before the decade including immigration $(M=13.10 ; S D=6.49)$. This latter difference only approaches significance $(t(9)=2.21, p=0.05)$, and this probably reflects the fact that for middle immigrators (age at immigration 24-28 and for later immigrators (age at immigration 34-35) the decade before immigration overlaps completely or in part with the traditional reminiscence bump. An alternate view of this graph might suggest that the experience of immigration in the mid to latter twenties of a person's life has the cognitive effect of extending the reminiscence phenomenon into adulthood. More conservatively, and similar to analyses that we have done earlier to test for the statistical reliability of the bump (Rubin and Schulkind, 1997a,b), the ten-year period that surrounds immigration contains more memories than the average of the two ten-year periods surrounding it $(M=22.40$; $S D=9.23$ versus $M=10.80, S D=4.87, t(9)=3.66, p<0.01)$.

The following four analyses are modelled on Fromholt and Larsen (1991).

\section{Amount of detail}

Memories were coded for amount of detail as follows: $1=$ Events reported in one single sentence (e.g. 'I was married in 1924'), 2 = Events reported with three additional pieces of information, and $3=$ Events reported with more elaborated content. In Table 1, memories are again grouped into ten-year periods surrounding the year of immigration set to zero, and mean amount-of-detail score reported for memories of each ten-year period. A repeated-measures ANOVA showed no significant difference between these means. Memories are reported with more or less the same amount of elaboration for events from across the lifespan. Put another way, there may be more memories for a particular period but these are recounted neither more elaborately nor plainly than memories for other periods.

\section{Backward versus forward search}

Though participants generally followed a chronological framework for developing their narratives, they occasionally doubled back and related events from previous years. Each 


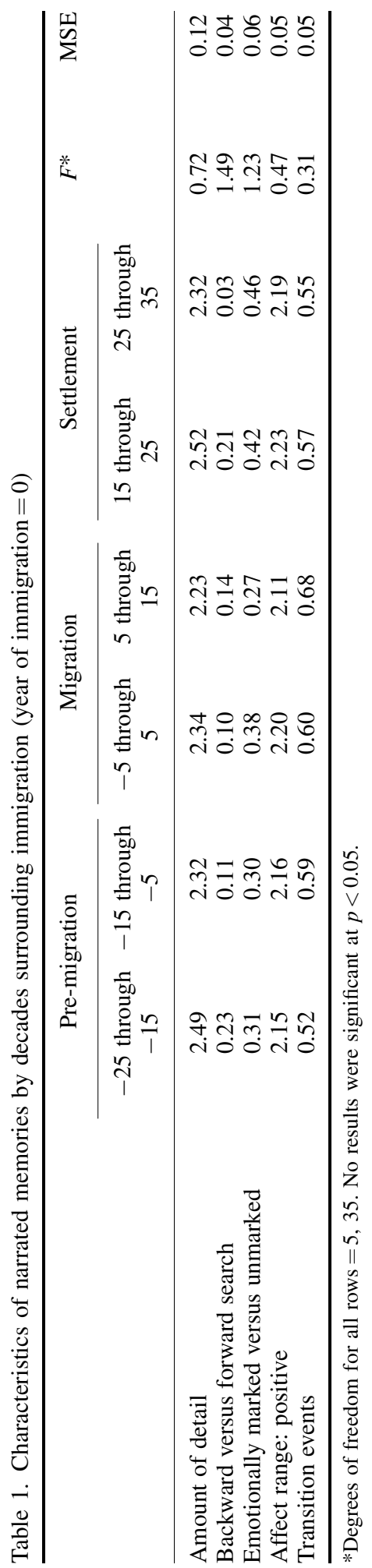


memory was therefore coded relative to the previous memory as either forward in time, backward in time or simultaneous with the memory that preceded it. Since in a chronological account backward search strategies are the exception and simultaneous searches are irrelevant for this analysis, scores represent the proportion of backward searches to forward searches. Table 1 shows that participants did not employ backward searches in any greater number for any particular period of life.

\section{Emotion}

Memories were rated for emotional valence by assigning a 1 for negative, 2 for neutral, and 3 for positive tone. Coding for positive or negative content required either that an explicit or implied emotional expression accompany the memory (i.e. 'That was a very sad time for us' or 'We got in trouble but we thought it was funny and didn't mind the trouble'). Two affect scores were generated: one for emotionally marked versus unmarked memories, and a second for the valence of emotion.

Because 2 indicates an emotionally neutral recounting of a memory, and 1 and 3 represent a marking of emotional tone, we first analysed the memories by testing for marked (scores of 1 or 3 ) versus unmarked (score of 2 ) memories. So, for example, were life in the homeland idealized and remembered with pleasure and life in the USA accounted flat and recounted with tedium, one would expect more emotionally marked memories for childhood, etc. Such does not occur, however. Table 1 shows no differences in emotional marking before, during, or after immigration. Alternatively, because scores towards 1 indicate negative construals and scores at 3 indicate positive construals, mean scores for all the memories of a particular period reflect the emotional tone of that period. Again, Table 1 shows no significant differences for tonality across the periods. For this group of immigrants, immigration and settlement are not recalled more happily or sadly, warmly or regretfully than any other period.

\section{Transitional events}

Memories were coded as representing a transitional event if the event set the stage for subsequent events (e.g. moving to a new city results in attending a new school, taking a job occasions new relationships) or brought about major changes in a person's life (e.g. marriage). Transitional events were scored 1; non-transitional events were scored 0 . One might expect that in the ten-year period of immigration and settlement, transitional events would predominate, but as Table 1 shows, the proportion of transitional vs. nontransitional events goes up only slightly during immigration. Looking across ten-year periods shows no significant differences among the proportions.

\section{DISCUSSION}

Consistent with the results from the cuing technique employed in Schrauf and Rubin (1998), participants' narrative recall of memories show distributions reflecting an increase of autobiographical recalls corresponding to the time of immigration. In conjunction with the finding of Conway and Haque (1999) for an increased number of recalls for older Bangladeshis for the period of the Bangladeshi revolution, this serves as a further argument that the reminiscence phenomenon is not simply a maturational effect observed 
only for the second decade of life and due to greater cognitive fitness during youth. Rather, these data suggest that the extensive psychological adaptation to major events such as revolution or immigration are also capable of significantly enhancing the encoding of autobiographical memories for particular periods of life.

What is striking about this phenomenon is that the evidence gleaned from the retrieval processes does not suggest appreciable differences in either the cognitive features or content of these memories. In terms of cognitive features, we predicted that memories for the period of immigration would be more detailed than memories for other times of life. Enhanced encoding, it would seem, should affect not only the number of memories encoded but the amount of detail as well. But this result does not obtain. More memories are recalled, but the average amount of detail seems to remain relatively constant.

Use of the narrative method permits some consideration of retrieval strategies within particular periods because participants are instructed to follow broadly a forward search strategy: 'Start at the beginning of your life and tell your story.' Since studies of autobiographical accounts of persons who have suffered major discontinuities in life report deviance from this chronological structure, we predicted that within periods of upheaval-during the decade of immigration - we would see more evidence of backward search. That is, we expected more cognitive 'jumping around'. Again, this result did not obtain. The proportion of backward to forward search remained relatively constant across the decades. It is possible, of course, that immigration does not present a 'discontinuous event', perhaps because its impact is lessened by social accompaniment in the cohort, or it is possible that in this sample of immigrants the work of hermeneutic integration has been smoothly accomplished. At any rate, at the time of retrieval, there is little evidence that this period differs from any other regarding memory search.

In short, we found no significant differences in cognitive features of autobiographical recalls for the period of immigration vs. other periods of life. Though immigration is accompanied by a numerical increase in the encoding of autobiographical memories (at least as evidenced in retrieval in later life), this exceptional encoding does not generate greater detail in recalls, and search strategies are not much changed.

Nor were there any differences in the content of memories from the period of immigration versus other periods. Because immigration is a stressful period, involving frequent trials, confirmations, and disconfirmations of an individual's sense of adequacy, we predicted that memories for events of that period would be more emotionally marked versus 'neutral'. Likewise, we suspected that the emotional tone of the period of immigration would be more positive (immigration as a good experience) or negative (immigration as a bad experience). There was, however, no evidence of more emotional markings for immigration in the narratives, and overall averages of emotional tone matched those of other periods of life. Finally, we predicted that immigration would be a time when memories for transitional events would outnumber memories for nontransitional (e.g. pleasant or annoying or intriguing memories but without consequence for the rest of life). This did not occur. While the absolute number of transitional memories increased for this time period versus other periods, the ratio of transitional to nontransitional memories did not change.

In sum, the memories for events corresponding to the time of immigration do not possess features of content that differentiate them from memories for other periods of life. They are neither more nor less emotional or significant than memories for other periods of life. They do not commemorate either more or fewer transitional events. Although surprising, these results are consistent with self ratings of memories obtained in studies 
using the word-cue method (Conway and Haque, 1999; Rubin and Schulkind, 1997a) in which ratings of emotion, vividness, pleasantness, significance, novelty, and frequency of rehearsal, as well as reaction-time measures did not vary over the lifespan. Accounting for these results has to do with a feature that is common to both the word-cued and narrative procedures: the participants choose the memories. This raises two possibilties. First, if memories from the decade of immigration were more marked on one of the attributes (more detailed or more emotionally salient or more transitional or more subject to backward search), then we might conclude that participants are 'selecting' (an unconscious process) more memories from the time of immigration because memories from that time are more salient on one or the other of these attributes. But we did not find that. Rather, the memories from the decade of immigration were no different on these attributes than memories from any other decade. A second possibility is that, to be 'selected' for retrieval, a memory must possess some required minumum of one or other of these attributes. In this case, all memories from all decades would possess these attributes similarly at some baseline (which is what we see). Then, if more memories are retrieved from the decade of immigration (as they are), we conclude that more memories met the minumum requirments for selection. This seems the likely explanation, and it suggests that the distinctive feature of memory for the decade of immigration is that more memories are recalled from that period.

At the most basic level our results show that immigration causes a change in the distribution of autobiographical memories over the lifespan. That is, when memories are retrieved in narrative format (the 'life-story'), more memories are recounted from the period during which immigration and early settlement occurred. In the introduction we described three theories to account for the traditional reminiscence bump of adoloscence and early adulthood: maturational-biological, identity, and cognitive mechanisms. The maturational-biological account suggests that the youthful cognitive mechanism possesses greater efficiency and speed in memory encoding during the period between the ages of 15 and 25 . This explanation does not extend to the middle and later immigration groups and may be discounted here.

The identity-development explanation suggests that there are more memories for ages 15 to 25 because it is a time of identity formation for the young adult. While this explanation might apply to the immigrant's forming a new cultural identity, it is weakened by the fact that many aspects of identity remain stable over the course of acculturation. For example, personality characteristics (e.g. 'impteuous', 'introspective') or family roles (e.g. 'father', 'daughter') would be unlikely to change radically (though new contexts can occasion the emergence of new patterns). Although the immigrant must re-engage issues of sociocultural identity, he or she does not begin with a tabula rasa as does the young adult, and therefore identity formation may not be as intense a psychological process as for the young adult. Nevertheless, the identify formation account is compatible with our finding an increase of memories during the time of immigration and settlement.

The cognitive mechanisms account has two basic components: increased encoding and spaced practice. On the encoding side, more effort after meaning during immigration is needed to understand the new cultural environment, and new schemata are being formed. Particularly during this time, 'prototypical events' are encoded, and these events provide the schemata for understanding ongoing events. On the rehearsal side, the new events and schemata are being retrieved at spaced intervals which increases the retention of the events whereas pre-migration events and their related schemata are being used less often (see Braun and Rubin; 1998; Rubin, 1995; Rubin et al., 1998, for reviews of these issues). In 
addition, immigration (as studied here) includes acquisition and daily use of a new language. Integration of new experiences (encoding) in another language requires greater effort, and suggests that the cultural and linguistic framing of new events is integrated into post-migration but not pre-migration cognitive structures. This latter suggests that memories for pre-migration events may not be as well integrated into newer cognitive structures. The cognitive mechanisms account provides a suitable explanation for our findings.

Another factor that may impinge on the experience of immigration is stress. Moderate levels of stress due to the experience of immigration could serve to increase encoding. Increased stress could work through the relevant cognitive mechanisms in that stressful situations would require more effort after meaning and more rehearsal (repeated retrievals in an effort to integrate the event).

These explanations suggest that immigration is indeed a traumatic event as described in the introduction to this paper. Immigration implies a shock to the mental organism-the acute phase described by the Grinbergs - that overtaxes normal abilities to integrate new experiences and information. In cognitive terms, greater effort after meaning is necessary (Bartlett, 1916, 1932). Sequelae include subsequent attempts to integrate these experiences - the delayed effects described by the Grinbergs. In cognitive terms, repeated and spaced rehearsal results in greater retention. The overall effect is increased retrievals for the period of immigration.

We might further consider the relation of the moderate levels of stress involved in immigration, as considered by Grinberg and Grinberg (1989), and the more severe stress of negative events that leads to posttraumatic stress disorder or amnesia for traumatic events. By most views, these situations involve two kinds of memories: the conscious, explicit memories of the type reported here, and unconscious, implicit memories, especially memories for powerful negative events, which cannot be reported (Brewin et al., 1996; McNally et al., 1995; Nadel and Jacobs, 1998). It is the lack of such powerful implicit memories for negative events that is probably the most important distinction between the kinds of stress caused by the voluntary migration of our participants and the kind of stress that leads to more negative outcomes for memory. In particular, the coherent life narratives that were obtained here are a sign that the stress of migration is different from that of more traumatic events (Barclay, 1996; Foa et al., 1995; van der Kolk and Fisler, 1995).

\section{ACKNOWLEDGEMENTS}

This research was supported by National Institute of Aging grant R01 AG16340-01A1.

\section{REFERENCES}

Barclay CR. 1986. Schematization of autobiographical memory. In Autobiographical Memory, Rubin DC (ed.). Cambridge University Press: Cambridge; 82-99.

Barclay CR. 1996. Autobiographical remembering: narrative constraints on objectified selves. In Remembering Our Past: Studies in Autobiographical Memory, Rubin DC (ed.). Cambridge University Press: New York; 94-125.

Barclay CR, Subramanian G. 1987. Autobiographical memory and self-schemata. Applied Cognitive Psychology 1: 169-182.

Barclay CR. Wellman HM. 1986. Accuracies and inaccuracies in autobiographical memories. Journal of Memory and Language 25: 93-103. 
Bartlett FC. 1916. An experimental study of some problems of perceiving and imaging. British Journal of Psychology 8: 222-266.

Bartlett FC. 1932. Remembering: A Study in Experimental and Social Psychology. Cambridge University Press: Cambridge.

Braun K, Rubin DC. 1998. The spacing effect depends on an encoding deficit, retrieval, and time in working memory: evidence from once presented words. Memory 6: 37-65.

Brewin CR, Dalgleish T, Joseph S. 1996. A dual representation theory of posttraumatic stress disorder. Psychological Review 103: 670-686.

Cerella J. 1985. Information processing rates in the elderly. Psychological Bulletin 98: 67-83.

Conway MA, Haque S. 1999. Overshadowing the reminiscence bump: memories of a struggle for independence. Journal of Adult Development 6(1): 35-44.

Crovitz HF, Schiffman H. 1974. Frequency of episodic memories as a function of their age. Bulletin of The Psychonomic Society 4: 517-551.

Elnick AB, Margrett JA, Fitzgerald JM, Labouvie-Vief G. 1999. Benchmark memories in adulthood: central domains and predictors of their frequency. Journal of Adult Development 6(1): 45-59.

Fitzgerald JM. 1986. Autobiographical memory: a developmental perspective. In Autobiographical Memory, Rubin DC (ed.). Cambridge University Press: New York; 122-133.

Fitzgerald JM. 1988. Vivid memories and the reminiscence phenomenon: the role of a self in narrative. Human Development 31: 261-273.

Fitzgerald JM. 1992. Autobiographical memory and conceptualizations of the self. In Theoretical Perspectives on Autobiographical Memory, Conway MA, Rubin DC, Spinnler H, Wagennar WA (eds). Kluwer: Boston, MA; 99-114.

Fitzgerald J. 1996. The distribution of self-narrative memories in younger and older adults: elaborating the self-narrative hypothesis. Aging, Neuropsychology, and Cognition 3(3): 229-236.

Foa EB, Molnar C, Cashman L. 1995. Change in rape narratives during exposure therapy for posttraumatic stress disorder. Journal of Traumatic Stress 8: 657-690.

Fromholt P, Larsen SF. 1991. Autobiographical memory in normal aging and primary degenerative dementia (Dementia of the Alzheimers type). Journal of Gerontology: Psychological Sciences 46: 85-91.

Fromholt P, Larsen P, Larsen SF. 1995. Effects of late-onset depression and recovery on autobiographical memory. Journal of Gerontology: Psychological Sciences 50B(2): P74-P81.

Grinberg L, Grinberg R. (ed.). 1989. Psychoanalytic Perspectives on Migration and Exile: Yale University Press: MI.

Hale S, Myerson J. 1995. Fifty years older, fifty percent slower? Meta-analytic regression models and semantic context effects. Aging and Cognition 2: 132-145.

Linde C. 1993. Life Stories: The creation of coherence. Oxford University Press: Oxford.

Luborsky M. 1987. Analysis of multiple life history narratives. Ethos 15: 366-381.

Luborsky M. 1993a. Continuity of Personal Meaning and Wellbeing in Later Life: Concepts, Critiques, and Findings. Philadelphia Geriatric Center: Philadelphia, PA.

Luborsky M. 1993b. The romance with personal meaning in gerontology, cultural aspects of life themes. The Gerontologist 33: 445-452.

Luborsky M. 1998. Creative challenges and the construction of meaningful life narratives. In Creativity and Successful Aging: Theoretical and Empirical Approaches, Adams-Price C (ed.). Springer Publishing: New York; 311-337.

McNally RJ, Lasko NB, Macklin ML, Pitman RK. 1995. Autobiographical memory disturbances in combat-related posttraumatic stress disorder. Behavior Research \& Therapy 33: 619-630.

Nadel L, Jacobs WJ. 1998. Traumatic memory is special. Current Directions in Psychological Science 7: 154-157.

Neugarten BL, Moore JW, Lowe JC. 1965. Age norms, age constraints, and adult socialization. American Journal of Sociology 70: 710-717.

Pillemer DB. 1998. Momentous Events, Vivid Memories: How Unforgettable Memories Help Us Understand the Meaning of our Lives. Harvard University Press: Cambridge, MA.

Rubin DC. 1995. Memory in Oral Traditions: The Cognitive Psychology of Epic, Ballads, and Counting-out Rhymes. Oxford University Press: New York.

Rubin DC. 1998. Autobiographical memory and aging: distributions of memories across the lifespan and their implications for survey research. In Cognition, Aging, and Self-reports, Schwarz N, Park DC, Knauper B, Sudman S (eds). Psychology Press: Philadelphia; 163-183. 
Rubin DC. in press. Autobiographical memory across the lifespan. In Lifespan Development of Human Memory, Graf P, Ohta N (eds). MIT Press: Cambridge, MA.

Rubin DC. Rahhal TA, Poon LW. 1998. Things learned in early adulthood are remembered best. Memory and Cognition 26(1): 3-19.

Rubin DC, Schulkind MD. 1997a. Distribution of important and word cued autobiographical memories in 20-, 35-, and 70-year-old adults. Psychology and Aging 12(3): 524-535.

Rubin DC, Schulkind MD. 1997b. The distribution of autobiographical memories across the lifespan. Memory and Cognition 25(6): 859-866.

Rubin DC, Wetzler SE, Nebes RD. 1986. Autobiographical memories across the lifespan. In Autobiographical Memory, Rubin DC (ed.). Cambridge University Press: New York; 202-221.

Salthouse TA. 1996. The processing-speed theory of adult age differences in cognition. Psychological Review 103: 403-428.

Schrauf RW. 1997. !Costalero quiero ser! Autobiographical memory and the oral life story of a holy week brother in Southern Spain. Ethos 25(4): 428-453.

Schrauf RW. 2000. Bilingual autobiographical memory: experimental studies and clinical cases. Culture \& Psychology 6(4): 387-417.

Schrauf RW. in press. Comparing cultures within subjects: a cognitive account of acculturation as a framework for cross-cultural study. Anthropological Theory.

Schrauf RW, Rubin DC. 1998. Bilingual autobiographical memory in older adult immigrants: a test of cognitive explanations of the reminiscence bump and the linguistic encoding of memories. Journal of Memory and Language 39(3): 437-457.

Schrauf RW, Rubin DC. 2000. Internal languages of retrieval: the bilingual encoding of memories for the personal past. Memory and Cognition 28(4): 616-623.

Settersten RA. 1997. The salience of age in the life course. Human Development 40(5): 257-281.

Settersten RA, Hagestad GO. 1996. What's the latest? Cultural age deadlines for educational and work transitions. The Gerontologist 36(5): 602-613.

Settersten RA, Mayer KU. 1997. The measurement of age, age structuring, and the life course. Annual Review of Sociology 23: 233-261.

van der Kolk BA, Fisler R. 1995. Disassociation and the fragmentary nature of traumatic memories: overview and exploratory study. Journal of Traumatic Stress 8: 505-525. 